\title{
ARTIGO
}

\section{COMPORTAMENTO FINANCEIRO DO ESTUDANTE: AVALIAÇÃO DA PROPENSÃO AO ENDIVIDAMENTO ${ }^{1}$}

\author{
Vanessa Piovesan Rossato ${ }^{2}$ \\ Nelson Guilherme Machado Pinto
}

\begin{abstract}
RESUMO
O objetivo do estudo foi identificar o comportamento financeiro dos estudantes de uma universidade no noroeste do estado do Rio Grande do Sul, avaliando as principais razões das dívidas das pessoas, aplicando uma survey com 160 alunos do curso de administração. Foram utilizadas técnicas de média aritmética e testes de diferença de média. As diferenças de média apontaram diferentes significados de propensão ao endividamento por gênero, idade, estado civil, filhos e renda. Os resultados mostraram-se significativos referentes ao perfil pela dívida por falta de planejamento, alta propensão ao consumo, falta de desconto à vista, empréstimo do nome e por acesso ao crédito. Os procedimentos apontaram que os respondentes gastam menos ou igual à renda que recebem, possuem dívidas, porém, não estão atrasadas e são mais cautelosos ao investir, uma vez que não desejam assumir riscos.
\end{abstract}

Palavras-Chave: Endividamento. Estudantes. Dívidas. Propensão. Administração.

\section{INTRODUÇÃO}

O dinheiro é um fator primordial nas organizações, visto que é através desse recurso que as pessoas têm a possibilidade de obtenção de materiais, de bens, e até mesmo a realização de pagamentos para a efetivação de um serviço. Destaca-se que atualmente há uma maior facilidade no que tange à obtenção dos produtos em geral, em razão do mercado oferecer inúmeras formas de pagamento, não sendo necessário possuir o dinheiro no momento da efetivação de compra.

Nota-se que há grande participação do público jovem na economia (FERNANDES; CANDIDO, 2014). Com isso, deve-se ter uma atenção mais especial a essa população, uma vez que se nessa fase já encontram dificuldades em gerir a saúde financeira, pode-se inferir que, no futuro, esses problemas se agravem ainda mais, trazendo prejuízos para a economia

\footnotetext{
${ }^{1}$ Como citar este artigo: ROSSATO, Vanessa Piovesan; PINTO, Nelson Guilherme Machado. Comportamento financeiro do estudante: avaliação da propensão ao endividamento. ForScience: revista científica do IFMG, Formiga, v. 7, n. 2, e00650, jul./dez. 2019. DOI: 10.29069/forscience.2019v7n2.e650.
}

${ }^{2}$ Autor para correspondência: Vanessa Piovesan Rossato, e-mail: vanessapiovesan@yahoo.com.br. 
do país (SERRA; LIMA, 2018). Nesse sentido, é de fundamental relevância trazer o tema do endividamento para o ambiente das universidades, meio no qual os jovens são preparados para se tornarem profissionais aptos ao mercado de trabalho. Dessa maneira, buscando conhecer o perfil dos jovens universitários e com os resultados obtidos dar um direcionamento mais eficiente para as políticas públicas, elaborando projeções que minimizem os impactos negativos sobre esse assunto.

O endividamento é propiciado, principalmente, pelas facilidades de crédito que incentivam o consumo de uma maneira exacerbada. Destaca-se que o ato de assumir dívidas não é ruim, o problema é quando as pessoas possuem dívidas e não assumem os compromissos financeiros, resultando na inadimplência (GUIMARÃES; ALMEIDA, 2013). Ressalta-se ainda que a situação mais delicada encontra-se no sobre endividamento, ou seja, quando os indivíduos se deparam numa fase em que ocorre a impossibilidade do pagamento das dívidas resultando em sérios problemas (MARQUES; FRADE, 2003; BRITO et al., 2018).

O estudo desenvolver-se-á em uma universidade localizada no noroeste do estado do Rio Grande do Sul. Posto isso, o objetivo do estudo é identificar o comportamento financeiro dos estudantes de uma universidade no noroeste do estado do Rio Grande do Sul, avaliando as principais razões das dívidas das pessoas.

A fim de consolidar a pesquisa, o estudo está segmentado em cinco seções. Após a introdução, segue o referencial teórico contemplando aspectos relacionados aos fundamentos do endividamento e finanças comportamentais. Em seguida, encontra-se o método, dando ênfase para os procedimentos adotados para a concretização da pesquisa. A quarta seção aborda as discussões dos resultados e por último as considerações finais destacando as principais limitações dessa pesquisa e sugestões para trabalhos futuros.

\section{REFERENCIAL TEÓRICO}

\subsection{Endividamento}

A palavra endividamento tem origem do verbo endividar, cujo significado baseia-se no ato de assumir e adquirir dívidas. Revela-se que o endividamento pode estar associado a algumas questões demográficas, como sexo, idade e estado civil, o que já foi comprovado em pesquisas como de Ponchio (2006) e Vieira, Flores e Campara (2015) em que as mulheres são 
mais propensas a fazer um uso inadequado do cartão de crédito e por essa razão obtendo problemas com dívidas pendentes (VIEIRA; FLORES; CAMPARA, 2015).

Quando o indivíduo solicita recursos de terceiros para o consumo de bens ou serviços, fica acordado que o mesmo deve devolver o ativo em determinada data, sendo que na maioria das vezes o montante é acumulado de juros. Diante disso, constata-se, que o endividamento é o saldo devedor de um agregado familiar (MARQUES; FRADE, 2003).

É comum associar o termo endividamento com inadimplência, entretanto, é importante enfatizar que esses dois tópicos possuem sentidos distintos. O primeiro está relacionado com o fato de utilizar-se de recursos de terceiros, já o segundo tem sua origem no descumprimento de um dever, podendo ser identificada como um risco de crédito (PINTO; CORONEL, 2012).

Em concordância com o exposto, os autores Nisiyama e Nakamura (2015) retratam que o endividamento leva o risco de inadimplência e em casos mais delicados a falência retratada pelo sobre endividamento. O sobre endividamento é a situação mais grave do endividamento, uma vez que a pessoa se torna incapaz de honrar os compromissos financeiros assumidos sem colocar em prática a subsistência da família. Essa situação ocorre quando as dívidas alcançam um patamar em torno de $75 \%$ de comprometimento das contas, ficando o endividado em grande risco financeiro (ZERRENNER, 2007; CAMPARA et al.,2016; BRITTO et al., 2018).).

Uma das formas das pessoas adquirirem dívidas é pelo cartão de crédito. Com esse método, os indivíduos muitas vezes perdem a percepção de quanto dinheiro foi disposto na compra dos produtos, posto que o dinheiro não precisa ser desembolsado na efetuação da compra (SILVA; NAKAMURA; MORAES, 2012). Entretanto, após a chegada da fatura do cartão de crédito, muitos indivíduos podem não ter condições de arcar com as contas, comprometendo parcela significativa de sua renda (KUNKEL; VIEIRA; POTRICH, 2015).

Durante muito tempo, acreditou-se que as pessoas tomavam suas decisões impulsionadas pela razão, num contexto de mercado eficiente em que fatores externos não detinham importância no processo de influência de decisão (ALVARENGA; VOSGERAU, 2015). No entanto, devido a algumas limitações dos modelos neoclássicos existentes em justificar a dinâmica dos mercados mundiais, emerge um novo campo de estudo, intitulado como finanças comportamentais, pressupondo que as pessoas agem de maneira irracional no processo de tomada de decisão financeira.

\subsection{Finanças Comportamentais}


As finanças comportamentais são uma ramificação das finanças gerais que exercem importância nas decisões relacionadas aos investimentos. Seu estudo fundamenta-se nos fatores que são responsáveis pela tomada de decisões (VIEIRA et al., 2015). Revela-se que o estudo e compreensão das finanças comportamentais fornecem vestígios de como serão as atitudes dos compradores em determinada situação (ROGERS; ROGERS; SECURATO, 2015).

A fundamentação das finanças comportamentais reverencia que as pessoas, muitas vezes, agem irracionalmente, pois estão subordinadas às marcas de desapontamentos cognitivos. Assim, o foco desse objeto de estudo condiz na análise de categorias comportamentais e psicológicas que podem influenciar no processo de decisão do agente acerca de processos financeiros (AGUIAR, 2006).

$\mathrm{O}$ estudo das finanças comportamentais enfoca que, por mais que as pessoas tentem a agir com racionalidade, há fatores externos psicológicos e comportamentais que influenciarão no processo de decisão de compra (MALAQUIAS; MAMEDE, 2015). De igual modo, Oliveira e Krauter (2015) referem que as finanças comportamentais negam que o mercado seja eficiente, e os tomadores de decisão sejam estimulados pela razão. Em virtude desse distanciamento da racionalidade com as decisões de investimento, as finanças comportamentais buscam aporte na ciência da Psicologia. Para tanto, são utilizados alguns métodos cognitivos desse conhecimento que buscam explicar esse afastamento (BARROS; FELIPE, 2015). Desse modo, é interessante ampliar os horizontes para outras áreas sociais, como a Psicologia, ao invés de restringir a pesquisa a um viés apenas de cunho econômico e financeiro (HAUBERT; LIMA; LIMA, 2014).

A ideia das finanças comportamentais não é limitar os postulados de finanças e economia, mas buscar uma fusão com a ciência psicológica, que estuda o excesso de confiança. Já se tem a noção de que os indivíduos são influenciados pelas experiências passadas, então, busca-se aprimorar esse impacto por meio de estudos enfáticos nesta área (ROSA; MILANI, 2015). Portanto, as finanças comportamentais vieram com o objetivo de alastrar os estudos do mercado social que, anteriormente, pela conjuntura tradicional, pecavase pela desconsideração de vetores importantes a serem analisados como os fatores psicológicos (ROGERS; ROGERS; SECURATO, 2015).

\section{MÉTODO}


O processo utilizado para atender aos propósitos desta pesquisa pode ser classificado como quantitativo, pois as informações coletadas são abordadas de forma estatística e o fornecimento de dados ocorre de forma mais precisa (HAIR et al., 2005). Para o alcance da amostra necessária da pesquisa foi utilizado o método survey, ou seja, o levantamento de dados que se fundamentam na coleta de informações primárias por meio das pessoas.

O instrumento utilizado para a coleta de dados foi um questionário (APÊNDICE A) elaborado para analisar a partir das respostas dos respondentes os fatores de propensão ao endividamento. $\mathrm{O}$ uso deste instrumento é justificado devido à utilização com grande frequência do mesmo em pesquisas que abordem esse tema (FLORES, 2012). O questionário desse estudo é composto por 24 questões fechadas e distribuídas em quatro blocos.

Bloco I - Dados referentes aos níveis de endividamento - Se possui dívidas, quais os tipos, quanto elas comprometem o orçamento do questionado, frequência com que o questionado consegue poupar.

Bloco II - Dados referentes ao nível de educação financeira - conhecimento para gerenciar o dinheiro, lugar em que adquiriu conhecimentos para gerir o dinheiro.

Bloco III - Dados referentes aos fatores de propensão ao endividamento, bem como o nível de propensão ao endividamento e de materialismo - principais razões das dívidas das pessoas e inclinação ao endividamento.

Bloco IV - Dados pessoais dos questionados - gênero, faixa etária, estado civil, renda familiar, grau de ensino, ocupação.

A população alvo do estudo é constituída por 371 alunos do curso de administração da universidade Federal de Santa Maria- Campus de Palmeira das Missões, sendo a amostra selecionada de 160 alunos. O trabalho constitui-se de uma amostra não probabilística por conveniência, ou seja, os elementos da amostra são selecionados de acordo com a conveniência do autor, sendo esta considerada uma limitação do estudo. Desse modo, o pesquisador seleciona apenas os elementos que tem acesso, admitindo que estes representem toda a população (GIL, 2008).

Precedente a aplicação dos questionários nas turmas de administração da universidade, foi realizado um pré-teste com 12 alunos da empresa júnior que constituem estudantes da universidade auferida, com o intuito de diagnosticar eventuais dúvidas que os respondentes obtivessem no desenvolvimento das respostas do questionário. Ademais, o questionário foi entregue a dois profissionais especializados para avaliação do mesmo, pedindo para que assinalassem as questões que não foram compreendidas dando contribuições para a melhoria 
do instrumento de coleta de dados. Portanto, com essa análise, três questões foram modificadas, mas nenhuma foi excluída da pesquisa.

O tipo de análise utilizada foi a descritiva, pois relatou-se o comportamento de uma variável em uma população, descobriu-se suas características e investigou-se a relação entre elas. De acordo com a temática descritiva, o pesquisador expõe as características de determinada população, para que se consiga estabelecer correlações entre as variáveis, definindo sua natureza (GIL, 2008).

Para análise dos dados empregou-se alguns testes estatísticos buscando primordialmente conhecer o perfil dos respondentes, realizando cálculos de média aritmética com as variáveis condizentes aos aspectos socioeconômicos correlacionado com os dois primeiros blocos do questionário, ou seja, nível de endividamento (Bloco A) e nível de educação financeira (Bloco B).

Em seguida, foi realizado testes não paramétricos, conforme o pressuposto de normalidade dos dados, de diferenças de média entre os grupos de ciclo de vida familiar com o intuito de avaliar a significância entre as variáveis. Assim, com a não normalidade dos dados, foram utilizados os testes não paramétricos U Mann Whitney para até dois grupos e o de Kruskal Wallis para mais de dois grupos. Esses testes possuem como hipótese nula o fato de não existir diferenças entre os grupos, e como hipótese alternativa a existência de diferenças entre os grupos (MALHOTRA, 2006).

\section{ANÁLISE DOS RESULTADOS}

A seguir, serão elucidados os principais resultados do estudo, que tecem os assuntos abordados até o presente momento. Enfatiza-se que para construção da pesquisa foram utilizados 160 questionários válidos, em que foram aplicados em estudantes de administração de uma universidade localizada no noroeste do estado do rio Grande do Sul. Assim, primeiramente serão debatidos os itens condizentes com a caracterização da amostra de estudo e posteriormente os testes de diferença de grupos $U$ de Mann-Whitney e a análise de variância de um fator de Kruskal-Wallis com objetivo de identificar as proposições que apresentam representatividade relacionada aos dados de perfil. De acordo com os procedimentos adotados, constata-se que os dados possuem distribuição não normal.

\subsection{Caracterização do perfil e do endividamento da amostra}


Ao relacionar o gênero dos estudantes de administração com o aspecto da existência de dívidas dos alunos, verificou-se que as mulheres apresentam uma frequência maior do que a dos homens, visto que $54,95 \%$ dos questionados que possuem dívidas são mulheres. Salienta-se que a maioria dessas pessoas não possuidoras de dívidas é solteira, representado por $86,27 \%$ dos questionados.

Foram questionados quais os tipos de dívidas que os estudantes possuem, a partir disso a que mais obteve destaque foi o tipo crediário à medida que quase $40 \%$ dos questionados têm esse tipo de contas a pagar. Das pessoas que adquirem dívidas por esse método, mostra-se a supremacia das mulheres, já que elas possuem um destaque de $61,82 \%$, confirmado pela pesquisa de Vieira, Flores e Campara, (2015) em que foi diagnosticado que as mulheres possuem uma predisposição maior a deixar de pagar a fatura do cartão de crédito, colaborando então para a dívida nesse quesito.

Ao analisar se as dívidas dos estudantes estão em atraso é notório que as estudantes do curso de administração possuem um controle mais rigoroso no que diz respeito ao cumprimento dos compromissos financeiros, visto que 58,82\% das alunas que possuem algum tipo de dívida conseguem honrar os pagamentos nas datas pré-estabelecidas. Além disso, percebe-se que mais da metade dos questionados a respeito de possuírem dívidas e se as mesmas estão em atraso encontram-se no público masculino com cerca de 69,23\%.

Os resultados da análise exemplificam que em média, quase metade dos alunos de administração $(45,71 \%)$, gasta menos do que ganha, isso evidencia que grande parte dos estudantes é cautelosa no que se refere ao controle de suas despesas. Confirma-se que as mulheres são mais cuidadosas nesse critério, visto que mais da metade $(57,81 \%)$, possuem um planejamento financeiro e, por conseguinte tendem a ter mais facilidade na organização das contas e consequentemente pagam seus deveres sem quaisquer dificuldades.

Entretanto, mais de um terço dos questionados (38,57\%) afirmam gastar na mesma proporção da quantia que recebem. Esse dado mostra que essas pessoas não se encontram numa situação de risco financeiro, no entanto situações inesperadas que possam vir a acorrer causariam dificuldades em se manter financeiramente, já que esses indivíduos não possuem a preocupação em manter uma reserva a fim de usar em algum tipo de emergência. De acordo com Marques e Frade (2003), uma pessoa endividada pode se tornar inadimplente à medida que não efetua os pagamentos de maneira pontual, esgotando-se as probabilidades de renegociação, levando ao julgamento tribunal.

Com relação à frequência em que se consegue poupar em relação ao gênero dos questionados, atenta-se que no geral a maior representatividade concentra-se na periodicidade 
de algumas vezes com 33,57\% com protagonismo da manhã. Destaca-se ainda que dessas pessoas que mantém essa continuidade de poupança, 65,96\% são mulheres, fato que fica ainda mais evidente nos respondentes do aspecto das pessoas que nunca conseguem poupar, visto que apesar da pouca representatividade de respondentes desse quesito (10\%), destaca-se que $64,29 \%$ desses, são mulheres.

A fim de mensurar o conhecimento dos alunos de administração a respeito de assuntos específicos financeiros, o questionário teve uma questão com o propósito de identificar se os alunos que possuem um contato direto com temas financeiros realmente sabem o valor do dinheiro no decorrer tempo. Diante disso, revela-se um resultado satisfatório, pois mais da metade dos estudantes $(67,14 \%)$ acertaram a questão. Identifica-se que as mulheres apresentaram destaque nessa pontuação, uma vez que possuem um peso de 55,32\% da amostra que responderam corretamente.

Referente à quantidade de risco que o entrevistado está disposto a assumir obtém-se como resposta a negação de assumir risco financeiro, com 33,33\%, ou seja, um terço dos respondentes destacado pela supremacia das mulheres visto que representam 55,32\% das pessoas que responderam esse item. De acordo com Potrich, Campara e Brutti, (2015), a tolerância menos representativa das mulheres é uma unanimidade na literatura, visto que normalmente elas estão dispostas a arriscar menos que os homens. Esse fato é confirmado á proporção que dos $9,22 \%$ que se mostram permissivos a assumir um maior risco, a maior parte são do sexo masculino com um destaque de 69,23\%.

Observando a questão que retrata sobre a antecipação dos jovens referente à iniciativa de formação de poupança para a futura aposentadoria, os resultados demonstram que mais de um terço $(39,72 \%)$ dos estudantes não se preocuparam em guardar dinheiro para a previdência. Esse fato pode ser explicado á medida que muitos dos respondentes são muito jovens e que grande parte é dependente dos pais, não ganhando recursos financeiros próprios para a concretização de uma poupança para essa finalidade. Por outro lado, com um percentual significativo de $38,30 \%$ estão as pessoas que possuem planos para começar a poupar dinheiro a fim de destinar para a aposentadoria. Esse fato é favorável, pois demonstra que muitas pessoas estão preocupadas com o seu futuro e almejam começar a guardar dinheiro para esse fim.

Observando como os questionados buscaram maiores conhecimentos financeiros em relação ao estado civil, ocorre a supremacia das experiências próprias. Nota-se grande parcela dos casados nesse quesito com um peso de 25,37\%. Assim, questões rotineiras da família, manutenção de uma casa são fatores rotineiros que agregam experiências para essas pessoas 
em virtude de já possuírem um lar para gerenciar. Em segundo lugar, aparecem as pessoas que extraem conhecimentos financeiros oriundos de conversas com a família com uma significância de 26,23\%, destaca-se ainda que considerável parte das pessoas que responderam essa questão são do sexo feminino com uma representatividade de 56,25\%.

Após isso se encontram as pessoas que adquirem maior conhecimento financeiro em aulas da faculdade, com o domínio das mulheres com 57,89\%. Por conseguinte, de acordo Vieira et al., (2016) infere-se que nenhuma forma de adquirir conhecimentos financeiros é mais eficaz do que a outra, sendo que existem variadas formas de desenvolver noções que tangem aspectos financeiros. Diante disso, o que deve ser levado em consideração nesse caso é que independente da maneira em que se busquem informações para um maior controle do fluxo financeiro do ser humano, é essencial que a fonte seja revertida em autoconhecimento e aprendizagem.

Adentrando-se na quantidade de risco que as pessoas estão dispostas a assumir, correlacionada com o estado civil dos estudantes, percebe-se que os solteiros possuem grande notabilidade, com a coragem de arriscar, com percentuais de $77,78 \%$ com a disposição de assumir um grande risco e 61,54 com a disponibilidade de assumir um risco financeiro acima da média. De acordo com os estudos de Flores, Vieira e Coronel (2013), as pessoas solteiras não possuem um compromisso financeiro intenso com a família, e por essa razão são mais propensos a arriscar com certa audácia e consequentemente podendo ser o público mais tendencioso a dívida.

Do mesmo modo, os casados por estarem inseridos em um contexto familiar que de certa maneira exige um compromisso mais rígido com a família, com as despesas em que muitas vezes está incluindo filhos e dependentes possuem maiores percepção ao risco que apesar de ser menor do que o risco tolerado pelos solteiros não deixa de ser um percentual significativo. Salienta-se que é de fundamental relevância entender a tolerância ao risco no sistema financeiro, pois assim conhecendo melhor o perfil das pessoas e qual o tamanho do risco que elas estão dispostas a assumir fica mais claro que ações devem ser desempenhadas em relação à tolerância ao risco (POTRICH; CAMPARA; BRUTTI, 2015).

A partir dos resultados obtidos, evidencia-se que alunos com renda entre seis e nove salários mínimos (35,29\%), declararam que conseguem poupar sempre. Nos estudos de Trindade et al., (2011) ratifica que quanto maior o nível de renda, maior será o seu comportamento financeiro. Essa informação é confirmada quando analisado as pessoas que possuem uma faixa salarial acima de nove salários, visto que o maior peso está concentrado nas pessoas que sempre conseguem poupar $(17,65 \%)$. Ademais, constata-se que não houve 
ocorrência de pessoas que ganham mais de 9 salários, que afirmam nunca conseguir poupar ou também que raramente conseguem poupar, evidenciando mais uma vez que indivíduos com maiores ativos possuem mais facilidade em poupar. A fim de sintetizar os principais resultados oriundos da estatística descritiva, o Quadro 1, faz um apanhado das relações estudadas com os resultados.

\begin{tabular}{|l|l|}
\hline \multicolumn{1}{|c|}{ Questão } & \multicolumn{1}{c|}{ Situação } \\
\hline Mulheres & $\begin{array}{l}\text { São as que possuem mais dívida e essas são causadas pelo cartão de } \\
\text { crédito. } \\
\text { Melhor planejamento financeiro }\end{array}$ \\
\hline Homens & Possuem mais dívidas em atraso \\
\hline Estudantes de Administração & $\begin{array}{l}\text { Pagam suas contas antes do prazo de vencimento; } \\
\text { Gastam menos do que ganham; }\end{array}$ \\
\hline Casados puantonentos. \\
\hline $\begin{array}{l}\text { Quantia de risco que as pessoas } \\
\text { estão dispostas a assumir }\end{array}$ & Possuem mais dificuldades para honrar os desejam assumir riscos financeiros \\
\hline Poupança & Estudantes ainda não se preocuparam com essa questão \\
\hline Fonte de conhecimento financeiro & Família \\
\hline
\end{tabular}

Quadro 1- Quadro Resumo dos principais resultados acerca da estatística descritiva

Fonte: Dados da pesquisa (2017).

Os resultados ratificam algumas considerações já analisadas a respeito dos aspectos do endividamento, como que as mulheres são mais propensas ao endividamento, colocação já identificada na pesquisa de Ponchio (2006). Salienta que uma das causas das dívidas refere-se ao alto consumo pelo crediário. Na perspectiva de Vilain e Pereira (2013), muitas vezes, o consumo é visto como sinônimo de luxo e status e na busca deste reconhecimento social, as pessoas comprometem sua renda e consequentemente ficam sem condições para honrar com compromissos assumidos.

\subsection{Comparação dos fatores relacionados ao endividamento}

Para saber os tipos de testes a serem utilizados, se paramétricos ou não paramétricos, foi realizado um teste de normalidade. No presente estudo, foi utilizado o teste de Kolmogorov-Smirnov (KS), para verificar o pressuposto de normalidade dos fatores. A hipótese nula foi a de que os dados possuem distribuição normal. Analisando o nível de significância (Sig) encontrado para as variáveis observasse que todas possuem o valor menor que $0,05(5 \%)$ e, portanto, deve-se rejeitar a hipótese nula. Dessa forma, não há normalidade entre os dados analisados devendo ocorrer a utilização de testes não paramétricos para verificar a diferença entre os grupos. Os testes a serem realizados foram o U de Mann- 
Whitney e a análise de variância de um fator de Kruskal-Wallis. Para os testes, a hipótese nula foi a de que não houve diferença no impacto do fator de causas entre os grupos.

Diante desse parecer, o primeiro constructo analisado refere-se às principais razões das dívidas das pessoas, relacionado ao gênero dos entrevistados, evidenciados na Tabela 1, a fim de identificar se o gênero influenciava na percepção sobre as principais causas das dívidas das pessoas. A partir desse princípio, foram realizados cruzamentos relativos às variáveis de perfil com as segmentações de razões das dívidas das pessoas, materialismo e propensão ao endividamento.

Tabela 1- Gênero versus dívidas

\begin{tabular}{lccc}
\hline Fator & $\begin{array}{c}\text { Média } \\
\text { Homens }\end{array}$ & $\begin{array}{c}\text { Média } \\
\text { Mulheres }\end{array}$ & Sig. \\
\hline Cheque especial & $\mathbf{0 , 1 5}$ & 0,03 & 0,0074 \\
Dívida por alta propensão ao consumo & 5,95 & $\mathbf{6 , 8 1}$ & 0,0484 \\
$\begin{array}{l}\text { Dívida por ausência de desconto à vista } \\
\text { Eu sei exatamente quanto devo em lojas, cartão de } \\
\text { crédito ou banco. }\end{array}$ & 2,63 & $\mathbf{3 , 4 6}$ & 0,0489 \\
$\begin{array}{l}\text { Possuo total controle das entradas e saídas do meu } \\
\text { dinheiro }\end{array}$ & 7,97 & $\mathbf{8 , 7 9}$ & 0,0335 \\
Pago minhas contas sem atraso & 7,16 & $\mathbf{8 , 3 6}$ & 0,0061 \\
\hline
\end{tabular}

Fonte: Dados da pesquisa (2017).

Salienta-se que referente às principais razões das dívidas das pessoas, as mulheres obtiveram destaque nas duas variáveis que alcançaram significância, uma vez que a média das estudantes foi superior a dos homens. Além disso, as alunas adquirem mais dívidas do que os homens pela ausência de descontos à vista. De acordo com Trindade et al., (2011), as mulheres têm maiores inclinações ao endividamento em razão da sua cultura de consumir em demasia, justificando então a maior média do gênero feminino nesse aspecto. Flores, Vieira e Coronel (2013) ratifica que as mulheres são mais predispostas a gastar mais por impulso e muitas vezes por esse descontrole acabam por enfrentar situações de endividamento.

Um aspecto pertinente a enfatizar é que as mulheres apesar de possuírem maiores médias em relação às principais razões de dívidas, também possuem maiores médias referente à organização e planejamento de suas contas. Além de possuírem controle satisfatório das entradas e saídas do dinheiro e pagam as dívidas sem atraso. 
Tabela 2 -Filhos versus Dívidas

\begin{tabular}{lccc}
\hline Fator & $\begin{array}{c}\text { Média } \\
\text { Com filhos }\end{array}$ & $\begin{array}{c}\text { Média } \\
\text { Sem filhos }\end{array}$ & Sig. \\
\hline Dívida por empréstimo do nome & $\mathbf{5 , 0 2}$ & 2,65 & 0,0155 \\
$\begin{array}{l}\text { Dívida por acesso ao crédito } \\
\text { As pessoas ficariam desapontadas comigo se } \\
\text { soubessem que tenho dívidas }\end{array}$ & $\mathbf{5 , 8 7}$ & 4,05 & 0,0227 \\
\hline
\end{tabular}

Fonte: Dados da pesquisa (2017).

Essa tabela buscou atrelar o perfil condizente com a existência ou não de filhos com questões financeiras que obtiveram significância. Percebe-se que todas variáveis que possuíram significância estão sob protagonismo das pessoas com filhos, revelando fortes diferenças de comportamento com aqueles que não possuem dependentes. Com isso, destacase que as pessoas com filhos possuíram mais dívidas nas questões de empréstimo do nome com média de 5,02 superior a das pessoas que não possuem filhos. Segundo Alves et al. (2013) 40\% das pessoas endividadas emprestam seu nome para outras pessoas, e na pesquisa de Campara et al. (2016), uma das principais razões das dívidas se dá pelo empréstimo do nome.

Os resultados revelaram significância nas dívidas por acesso ao crédito, obtendo destaque o público respondente com filhos. Esses fatores podem ser explicados, pois pessoas com filhos possuem mais despesas, mais contas a pagar, sendo que muitas vezes o ativo que recebem não seja suficiente e acabam contraindo dívidas. De acordo com Wang Lu e Malhotra (2011), a existência de filhos corrobora para a presença de mais compromissos financeiros. Nesse sentido, precisam de mais recursos e, por muitas vezes não conseguirem comprar à vista os bens e serviços, optam por parcelar as compras.

Um aspecto que chama atenção e que obteve significância nos procedimentos estatísticos é referente à propensão ao endividamento na variável de que as pessoas em geral ficariam desapontadas se soubessem que o questionado possui dívidas. Ressalta-se que houve supremacia desse tópico das pessoas com dívidas, á medida que elas possuem média de 3,4 sendo superior com o das pessoas que não possuem dívidas na qual a média é de 1,5. Infere-se que esse resultado é fruto de uma pressão social á medida que há muito conflito por parte da comunidade com as pessoas que possuem dívidas, sendo muitas vezes rejeitadas pela sociedade e muitas vezes por essa exclusão as pessoas desenvolvem doenças como depressão, perturbações ansiosas e muito stress (ARTIFON; PIVA, 2014).

Assim a existência de indivíduos que dependam da renda de uma pessoa endividada gera angústia, pois se as contas não forem bem gerenciadas podem levar ao sobre endividamento dos respondentes colocando a família do entrevistado em risco. De acordo 
com Marques; Frade (2003), o sobre endividamento pode levar a exclusão do convívio social da família, colocando-se a mercê de julgamentos da sociedade. Com isso, a Tabela 3 faz alusão à significância com o estado civil.

Tabela 3 - Estado Civil Versus Dívidas

\begin{tabular}{|c|c|c|c|c|c|}
\hline Fator & $\begin{array}{l}\text { Média } \\
\text { Casado }\end{array}$ & $\begin{array}{c}\text { Média } \\
\text { União } \\
\text { Estável }\end{array}$ & $\begin{array}{c}\text { Média } \\
\text { Solteir } \\
\text { o }\end{array}$ & $\begin{array}{c}\text { Média } \\
\text { Divorciado }\end{array}$ & Sig \\
\hline Possui dívidas & $\mathbf{0 , 8 8}$ & $\mathbf{0 , 8 8}$ & 0,55 & 0,33 & 0,0022 \\
\hline Financiamento de bem móvel & 0,36 & 0,31 & 0,06 & - & 0,0001 \\
\hline Financiamento de bem imóvel & 0,36 & 0,31 & 0,05 & - & 0,0000 \\
\hline Dívida por falta de planejamento & 7,24 & 4,38 & 6,79 & 3 & 0,0274 \\
\hline $\begin{array}{l}\text { Admiro pessoas que possuem casas, carros e } \\
\text { roupas caras }\end{array}$ & 3,76 & 4,81 & 4,55 & 0,33 & 0,0486 \\
\hline Gosto de gastar dinheiro com coisas caras & 2,60 & 2,88 & 3,46 & 0,33 & 0,0116 \\
\hline $\begin{array}{l}\text { Prefiro comprar parcelado a esperar ter dinheiro } \\
\text { para comprar à vista }\end{array}$ & 6,12 & 5,63 & 4,30 & 1,67 & 0,0144 \\
\hline $\begin{array}{l}\text { As pessoas ficariam desapontadas comigo se } \\
\text { soubessem que tenho dívidas }\end{array}$ & 2,28 & 2,81 & 3,53 & 0,33 & 0,0291 \\
\hline
\end{tabular}

Fonte: Dados da pesquisa (2017).

Observa-se conforme a tabela que as pessoas que estão casadas ou em uma união estável apresentam mais dívidas comparados com aqueles que são solteiros ou divorciados. Isso pode ser explicado em parte, à medida que as pessoas que possuem um cônjuge possuem mais compromissos financeiros do que aqueles que estão solteiros, muitas vezes tendo a existência de filhos, justificando a presença de dívidas desse tipo de público.

Com equidade nos valores de média de pessoas casadas e em união estável, identificase que essas pessoas possuem médias superiores nas dívidas por financiamento de bem imóvel e móvel. Uma das causas das dívidas dos respondentes pode estar atrelada a um mau gerenciamento das contas o que á comprovado pela assertiva por falta de planejamento, uma vez que sua média é de 7,24, e as pessoas solteiras que possuem 6,79. Congruente ao exposto, as pessoas casadas, preferem fazer suas compras em parcelas, possuindo maior propensão ao endividamento.

No quesito gostar de gastar dinheiro com coisas caras, é visível a supremacia das médias das pessoas solteiras, uma vez que resultou num dado de 3,46. Esse fato é exemplificado à medida que pessoas solteiras não têm a responsabilidade de guardar o dinheiro para o bem-estar da família, caso ocorra algum imprevisto, justificando gastos com coisas caras. Nesse sentido, identifica-se que as pessoas casadas ou em união estável são as preferem pagar mais no cartão de crédito, consequentemente possuindo mais dívidas, e os solteiros têm propensão ao endividamento à medida que gostam de gastar dinheiro com coisas 
caras. A última variável que apresentou significância refere-se ao estado civil relacionado ao endividamento exposto na Tabela 4.

Tabela 4- Renda Versus Dívidas

\begin{tabular}{lcccccc}
\hline Fator & $\begin{array}{c}\text { Média } \\
\text { Até 1 } \\
\text { salário } \\
\text { mínim } \\
\mathbf{0}\end{array}$ & $\begin{array}{c}\text { Média } \\
\text { De 1 a 3 } \\
\text { salários } \\
\text { mínimos }\end{array}$ & $\begin{array}{c}\text { Média } \\
\text { De 3 a 6 } \\
\text { salários } \\
\text { mínimos }\end{array}$ & $\begin{array}{c}\text { Média } \\
\text { De 6 a 9 } \\
\text { salários } \\
\text { mínimos }\end{array}$ & $\begin{array}{c}\text { Mcima de 9 } \\
\text { salários } \\
\text { mínimos }\end{array}$ \\
\hline $\begin{array}{l}\text { Possui dívidas } \\
\begin{array}{l}\text { Crediário } \\
\text { Gosto de gastar dinheiro com } \\
\text { coisas caras }\end{array}\end{array}$ & 0,46 & 0,70 & $\mathbf{0 , 7 3}$ & 0,42 & 0,63 & 0,0476 \\
$\begin{array}{l}\text { Gastar muito dinheiro está } \\
\text { entre as coisas mais }\end{array}$ & 3,08 & 2,62 & 4,20 & 2,42 & $\mathbf{1 0}$ & 0,0143 \\
$\begin{array}{l}\text { importantes da minha vida } \\
\text { É importante saber controlar } \\
\text { os gastos da minha casa }\end{array}$ & 3,07 & 1,37 & 2,69 & 1,61 & $\mathbf{3 , 2 3}$ & 0,0143 \\
\hline $\begin{array}{l}\text { Fonte: Dados da pesquisa } \\
\text { (2017) }\end{array}$ & 8,54 & 8,47 & 9,31 & 9,38 & $\mathbf{9 , 7 5}$ & 0,0185 \\
\hline
\end{tabular}

Fonte: Dados da pesquisa (2017).

Ao analisar a faixa salarial dos alunos relacionando com questões financeiras identifica-se que as pessoas que têm entre três e seis salários mínimos são os maiores atores relacionados à existência de dívidas, visto que a média desse público foi diagnosticada como 0,73. Identifica-se que nas dívidas do tipo crediário, ocorre uma equidade nas médias das pessoas que possuem uma renda nas faixas de um a três salários mínimos e de três a seis salários mínimos, posto que seus resultados apresentaram igualdade de 0,47. A partir disso, infere-se que as pessoas com faixa salarial menos possuem mais dívidas e que são representadas em sua maioria pelo crediário.

Em relação a assertiva "gastar muito dinheiro está entre as coisas mais importantes da minha vida"notou-se forte propensão ao risco de endividamento das pessoas com maiores rendas. Esse fato desperta atenção à medida que se as pessoas sentem prazer em gastar, correm o risco de comprar produtos supérfluos sem se dar conta do total despendido nos valores da compra, podendo resultar em dificuldades no pagamento dos compromissos financeiros (MESSIAS; SILVA; SILVA, 2015).

Portanto, considera-se que houve diferenças significativas nos resultado referentes renda, reforçando a ideia de que as pessoas com rendas inferiores possuem mais dívidas. No entanto, os indivíduos que possuem maior faixa salarial são propensos a possuírem dívidas, posto que seus comportamentos de gostar de comprar, principalmente coisas caras, os impulsionam para um estado de endividamento. É de protagonismo das pessoas com maiores rendas a ideia de que é importante planejar os gastos, evidenciando que por mais que essa 
faixa etária tem fortes tendências de consumo exacerbado, possuem a consciência de controlar as despesas familiares.

\section{CONSIDERAÇÕES FINAIS}

Partindo do objetivo da pesquisa de identificar o comportamento financeiro dos estudantes de uma universidade no noroeste do estado do Rio Grande do Sul, foram obtidos os resultados esperados, por meio das respostas dos estudantes da universidade designada, acerca dos fatores de propensão ao endividamento das pessoas. Pode-se constatar que a maior parte dos respondentes se concentra no sexo feminino e que dentre os tipos de dívidas existentes o que mais se destacou foi o do tipo crediário. Além disso, evidencia-se que apesar de grande parte dos questionados possuírem dívidas, as mesmas em sua maioria não se encontram atrasadas.

No que tange o conhecimento financeiro das pessoas para gerenciar o dinheiro, identificou-se que estão razoavelmente seguros, mostrando-se aptos para administrar seus ativos. Além disso, foi diagnosticado que a maioria dos estudantes é mais cautelosa no quesito investimentos, visto que grande parte optou pelo investimento em poupanças e bens. Isso se deve, também, por parcela dos respondentes possuírem família e muitos deles já terem dependentes, sendo então menos propensos a investir em ações que possam colocar em risco suas famílias.

Ao analisar a questão que tinha como objetivo identificar se os alunos possuíam noção do dinheiro ao longo do tempo, contata-se que o resultado foi satisfatório, pois a maior parte assinalou a alternativa correta. Referente aos procedimentos estatísticos nota-se que ocorreu significância das dívidas por alta propensão ao consumo e ausência de descontos a vista ressaltado pela supremacia das mulheres. Entretanto, elas possuem mais controle de suas dívidas e sabem exatamente o que devem em lojas, cartão de crédito e banco, além de normalmente pagar suas contas sem atraso. Ao observar as pessoas com filhos, identifica-se que houve significância das pessoas que possuem dívidas por empréstimo do nome e por acesso ao crédito.

Por fim, as pessoas que se encontram numa faixa etária de um a três salários mínimos possuem mais dívidas, sendo que o tipo crediário se destaca mais. Nota-se que a média das pessoas que ressaltaram a importância de controlar os gastos para gerenciar a casa é alta em todas as rendas, entretanto, a que possuiu maior nota foi a de estudantes com renda superior a 9 salários mínimos. 
Algumas limitações foram encontradas para a concretização da pesquisa, como o próprio questionário, visto que os resultados obtidos se dão conforme a confiabilidade das respostas dos entrevistados, além dos elementos da amostra serem selecionados de acordo com a conveniência do autor. Ressalta-se também a não generalização dos resultados, posto que os achados retratam apenas a realidade estudada, não podendo ser expandida para outros cenários. Como sugestão de trabalhos futuros, indica-se a ampliação da amostra para todos os cursos da universidade que ocorreu essa pesquisa, além de aplicar esse método com outros os professores, servidores, empresários e terceirizados do ambiente estudantil. Também sugerese avaliar relações de causa e efeito do endividamento considerando a natureza sistêmica e psicológica desse fenômeno.

\title{
STUDENT'S FINANCIAL BEHAVIOR: ASSESSMENT OF THE PROPERTY TO THE DEBT
}

\begin{abstract}
The objective of this study was to identify the financial behavior of students from a university in the northwest of Rio Grande do Sul state, evaluating the main reasons for the debts of the people, applying a survey with 160 students of the administration course. Arithmetic mean and difference mean tests were used. The differences in the mean showed different meanings of debt propensity by gender, age, marital status, children and income. The results were significant in relation to the debt profile due to lack of planning, high propensity to consumption, lack of cash discount, name loan and access to credit. The procedures indicated that respondents spend less than or equal to the income they receive, have debt, but are not late and are more cautious when investing, as they do not want to take risks.
\end{abstract}

Keywords: Indebtedness. Students. Debts. Propensity. Administration.

\section{REFERÊNCIAS}

AGUIAR, S. Integração das Ferramentas da qualidade ao PDCA e ao Programa Seis Sigma. 2. ed. Nova Lima, MG: INDG TECS, 2006.

ALVARENGA, G. L.; VOSGERAU, D.S.R. Arrependimento, sunk cost e dor de corno: vivendo com as consequências das decisões. Pensamento \& Realidade, Revista do Programa de Estudos Pós-Graduados em Administração-FEA, v. 30, n. 2, 2015. Disponível em: https://revistas.pucsp.br/pensamentorealidade/article/view/24619. Acesso em: 12 jul. 2017.

ALVES, G. L. C.; MAHMOUD, B. D. O. R.; NASCIMENTO, B.; SAMPAIO, Y.; BACHA, M, 1. Baixa renda: endividamento e compreensão de notícias econômicas. Inovcom, v. 5, n. 2, p. 38-51, 2013. Disponível em: 
https://www.researchgate.net/publication/261134390_Baixa_renda_endividamento_e_compre ensao_de_noticias_economicas. Acesso em: 01 maio 2017.

ARTIFON, S.; PIVA, M. Endividamento nos dias atuais: fatores psicológicos implicados neste processo. Endividamento e implicações psíquicas. Psicologia.pt, p. 1-41, 2014.

Disponível em: https://www.psicologia.pt/artigos/ver_artigo.php?codigo=A0771. Acesso em: dez. 2017.

BARROS, T. S.; FELIPE, I. J. D. S. Teoria do prospecto: evidências aplicadas em finanças comportamentais. Revista de Administração FACES Journal, v. 14, n. 4, p. 75-95, 2015. Disponível em: http://www.fumec.br/revistas/facesp/article/view/2934. Acesso em: 09 ago 2017.

BRITTO, B. S. M.; OLIVEIRA-CASTRO, J. M.; HOLANDA, A. O.; SANTOS, T. L. D. Comportamento do Consumidor: Comparação entre Valor Relatado e Valor Gasto com Cartão de Crédito. Contabilidade, Gestão e Governança, v. 21, n. 3, p. 402-419, 2018. Disponível em: https://www.revistacgg.org/contabil/article/view/1568. Acesso em: jan. 2019.

CAMPARA, J. P.; VIEIRA, K. M.; COSTA, V. M. F; FRAGA, L. S. O Dilema dos Inadimplentes: Antecedentes e Consequentes do" nome sujo". REMark, v. 15, n. 1, p. 71-85, 2016. Disponível em: http://www.revistabrasileiramarketing.org/ojs2.2.4/index.php/remark/article/viewArticle/2941. Acesso em: jul. 2017.

FERNANDES, A. H. S.; CANDIDO, J. G. Educação financeira e nível do endividamento: relato de pesquisa entre os estudantes de uma instituição de ensino da cidade de São Paulo. Revista Eletrônica Gestão e Serviços, v. 5, n. 2, p. 894-913, 2014. Disponível em: https://www.passeidireto.com/arquivo/63409876/educacao-financeira-e-nivel-do-endividam. Acesso em: 11 out. 2017.

FLORES, S. A. M.; VIEIRA, K. M.; CORONEL, D. A. Influência de Fatores Comportamentais na Propensão ao Endividamento. Revista de Administração FACES Journal, v. 12, n. 2, p. 13-35, 2013. Disponível em: http://www.fumec.br/revistas/facesp/article/view/808. Acesso em: out. 2017.

FLORES, S. A. M. Sabrina Arruda. Modelagem de equações estruturais aplicada à propensão ao endividamento: uma análise de fatores comportamentais, 2012. Dissertação de Mestrado. Universidade Federal de Santa Maria. Disponível em:

https://repositorio.ufsm.br/bitstream/handle/1/4621/FLORES,\%20SILVIA\%20AMELIA\%20 MENDONCA.pdf. Acesso em: 12 mar. 2018.

GIL, A.C. Como elaborar projetos de pesquisa. 4.ed. São Paulo: Atlas, 2008.

GUIMARÃES, A. Q.; ALMEIDA, M. E. Os jovens e o mercado de trabalho: evolução e desafios da política de emprego no Brasil. Temas de administração pública, v. 8, n. 2, 2013. Disponível em: https://periodicos.fclar.unesp.br/temasadm/article/view/6845. Acesso em: 13 sete. 2017.

HAIR, J.; BABIN, B.; MONEY, A.; SAMOUEL, P. Fundamentos de métodos de pesquisa em administração. São Paulo: Bookman, 2005. 
HAUBERT, F. L. C.; LIMA, C. R. M.; LIMA, M. V. A. Finanças comportamentais: uma investigação com base na teoria do prospecto e no perfil do investidor de estudantes de cursos stricto sensu portugueses. Revista de Ciências da Administração, v. 16, n. 38, p. 183-195, 2014. Disponível em: https://periodicos.ufsc.br/index.php/adm/article/view/21758077.2014v16n38p183. Acesso em: 15 out. 2017.

KUNKEL, F. I. R.; VIEIRA, K.M.; POTRICH, A.C.G. Causas e consequências da dívida no cartão de crédito: uma análise multifatores. Revista de Administração, v. 50, n. 2, p. 169182, 2015. Disponível em: http://www.scielo.br/scielo.php?pid=S008021072015000200169\&script=sci_abstract\&tlng=pt. Acesso em: 14 nov. 2017.

MACEDO Jr., J. S. A Árvore do Dinheiro: guia para cultivar a sua independência financeira. Rio de Janeiro: Elsevier, 2007.

MALAQUIAS, F. R.; R.; MAMEDE, S. P. N. S. Efeito calendário e finanças comportamentais no segmento de fundos multimercados. RAC-Revista de Administração Contemporânea, v. 19, p. 98-116, 2015. Disponível em:

http://www.scielo.br/scielo.php?pid=S1415-

65552015000700007\&script=sci_abstract\&tlng=pt. Acesso em: 03 dez. 2017.

MALHOTRA, N. Pesquisa de marketing: uma orientação aplicada. 4. ed. Porto Alegre: Bookman, 2006.

MARQUES, M. M. L.; FRADE, C. Regular o sobreendividamento. Gabinete de Política Legislativa e Planeamento do Ministério da Justiça (Ed.). Código da Insolvência e da Recuperação de Empresas. Coimbra: Coimbra Editora, 2003. Disponível em: http://docplayer.com.br/. Acesso em: abr. de 2017.

MESSIAS, J. F.; DA SILVA, J. U.; SILVA, P. H. C. Marketing, Crédito \& Consumismo: Impactos sobre o endividamento precoce dos jovens Brasileiros. Revista Eniac Pesquisa, v. 4, n. 1, p. 43-59, 2015. Disponível em: file:///C:/Users/USER/Downloads/DialnetMarketingCreditoConsumismo-5261082.pdf. Acesso em: 08 mar. 2018.

NISIYAMA, E. K.; NAKAMURA, W. T. Pesquisas internacionais recentes em estrutura de capital/recent international research in capital structure. Revista de Administração de Roraima, v. 5, n. 1, p. 105, 2015. Disponível em:

https://dialnet.unirioja.es/servlet/articulo?codigo=5164427. Acesso em: 09 mar. 2018.

OLIVEIRA, R. L.; KRAUTER, E. Teoria do Prospecto: como as Finanças Comportamentais Podem Explicar a Tomada de Decisão. Revista Pretexto, v. 16, n. 3, p. 106-121, 2015. Disponível em: http://www.fumec.br/revistas/pretexto/article/view/1863/artigo. Acesso em: 11 abr. 2018.

PINTO, N. G. M.; CORONEL, D. A. Inadimplência no serviço de TV por assinatura: um estudo sobre as suas causas em uma empresa do setor da cidade de Santa Maria-RS. Sinergia, v 16, n 2, p. 41-51, 2012. Disponível em:

https://periodicos.furg.br/sinergia/article/view/3671/242. Acesso em: 05 abr. 2018.

PONCHIO, M. Canniatti. The Influence of Materialism on Consumption Indebtedness in the Context of Low Income Consumers from the City of Sao Paulo. 2006. $175 \mathrm{f}$. Tese (Doutorado em Administração de Empresas) - Escola de Administração de Empresas de São Paulo da Fundação Getulio Vargas, São Paulo, 2006. Disponível em: 
https://bibliotecadigital.fgv.br/dspace/bitstream/handle/10438/2519/142172.pdf?sequence=2\& isAllowed=y. Acesso em: nov. 2017.

POTRICH, A. C. G.; CAMPARA, J. P.; BRUTTI, F. Entendendo a tolerância ao risco: uma análise a partir das variáveis socioeconômicas e demográficas. In: ENCONTRO NACIONAL DE ENGENHARIA DE PRODUÇÃO FORTALEZA( ENEGEP)., XXXV, Fortaleza. Anais [...] ENEGEP: Fortaleza, 2015. Disponível em:

http://www.abepro.org.br/biblioteca/TN_WIC_208_236_26369.pdf. Acesso em: Setembro de 2017.

POTRICH, A. C. G.; VIEIRA, K. M.; KIRCH, G. Você é Alfabetizado Financeiramente? Descubra no Termômetro de Alfabetização Financeira. BASE - Revista de Administração e Contabilidade da UNISINOS, v. 13, n. 2, p. 153-170, 2016. Disponível em: https://bibliotecadigital.fgv.br/dspace/handle/10438/18826. Acesso em: 20 mar. 2017.

ROGERS, P.; ROGERS, D.; SECURATO, J. R. Forum: - About psychological variables in application scoring models. Revista de Administração de Empresas, v. 55, n. 1, p. 38-49, 2015. Disponível em: http://www.scielo.br/scielo.php?script=sci_arttext\&pid=S003475902015000100038. Acesso em: 12 jun. 2017.

ROSA, I. R. DA; MILANI, B. Aversão ao risco financeiro: um estudo sobre o comportamento de estudantes de nível superior. Caderno Profissional de Administração UNIMEP Mestrado Profissional e Doutorado em Administração, v. 5, n. 2, p. 84- 102, 2015. Disponível em: http://www.spell.org.br/documentos/ver/39612/aversao-ao-risco-financeiro-um-estudo-sobre-o-comportamento-de-estudantes-de-nivel-superior. Acesso em: 03 maio 2017.

SERRA, G.; P.; LIMA, G. T. Sustentabilidade do Endividamento Estudantil em uma Macrodinâmica Liderada pela Demanda. Economia e Sociedade, v. 27, n. 2, 2018. Disponível em: http://www.scielo.br/scielo.php?script=sci_abstract\&pid=S0104$06182018000200493 \& \operatorname{lng}=$ pt\&nrm=iso. Acesso em: $12 \mathrm{dez} .2018$.

SILVA, M. W. D A; NAKAMURA, W.T.; MORAES, D.C. Credit card risk behavior on college campuses: evidence from Brazil. BAR-Brazilian Administration Review, v. 9, n. 3, p. 351-373, 2012. Disponível em:

http://www.scielo.br/scielo.php?script=sci_arttext\&pid=S1807-76922012000300007. Acesso em: 14 set. 2017.

TRINDADE, L. L.; VIEIRA, K. M.; CERETTA, P. S.; CAVALHEIRO, E. A. Determinantes da propensão ao endividamento: um estudo nas mulheres da mesorregião Centro Ocidental Rio Grandense. Espacios (Caracas), v. 32, p. 18-20, 2011. Disponível em: https://repositorio.ufsm.br/handle/1/4550. Acesso em: 05 ago. 2017.

VIEIRA, K. M.; FLORES, S. A. M.; CAMPARA, J. P. Propensão ao Endividamento no Município de Santa Maria (RS): verificando diferenças em variáveis demográficas e culturais. TPA -Teoria e Prática em Administração, v. 4, n. 2, p. 180-205, 2015. Disponível em: https://periodicos.ufpb.br/ojs/index.php/tpa/article/view/19582. Acesso em: 15 set. 2017.

VIEIRA, K. M. KUNKEL, F. R.; CAMPARA, J. P.; PARABONI, A. L Alfabetização financeira dos jovens universitários rio-grandenses. Desenvolve Revista de Gestão do 
Unilasalle, v. 5, n. 1, p. 107-133, 2016. Disponível em: https://revistas.unilasalle.edu.br/index.php/desenvolve/article/view/2316-5537.16.17. Acesso em: 08 ago. 2018.

VILAIN, J. S. B.; PEREIRA, M. F. O impacto do status no planejamento financeiro pessoal: estudo de caso com os advogados de Florianópolis, Santa Catarina. Revista Gestão e

Planejamento, v. 14, n. 3, p. 470-488, 2013. Disponível em: https://repositorio.ufsc.br/handle/123456789/121435. Acesso em: 11 nov. 2017.

WANG, L; LU, W; MALHOTRA, N. K. Demographics, attitude, personality and credit card features correlate with credit card debt: A view from China. Journal of economic psychology, v. 32, n. 1, p. 179-193, 2011. Disponível em: https://www.sciencedirect.com/science/article/pii/S0167487010001327. Acesso em: 08 set. 2018.

ZERRENNER, Sabrina Arruda. Estudo sobre as razões para o endividamento da população de baixa renda. 2007. Tese de Doutorado. Universidade de São Paulo. Sisponível em: https://www.teses.usp.br/teses/disponiveis/12/12139/tde-13112007-120236/pt-br.php Acesso em: 09 nov. 2017.

\section{DADOS DOS AUTORES:}

\section{Vanessa Piovesan Rossato}

E-mail: vanessapiovesan@yahoo.com.br Currículo lattes: http://lattes.cnpq.br/1254235351711558

Mestranda em Administração pela Universidade Federal de Santa Maria (PPGA- UFSM), e graduada em Administração pela UFSM.

\section{Nelson Guilherme Machado Pinto}

E-mail: nelguimachado@ hotmail.com

Currículo lattes: http://lattes.cnpq.br/5647891554789516

Doutorado, mestrado e bacharelado em Administração pela UFSM.

Professor Adjunto da Universidade Federal de Santa Maria (UFSM), Professor do Programa de Pós-Graduação em Administração Pública e Professor do Programa de Pós-Graduação em Gestão de Organizações Públicas da Universidade Federal de Santa Maria (PPGOP/UFSM). 


\section{APÊNDICE A}

\section{Você possui dívidas/financiamentos?}

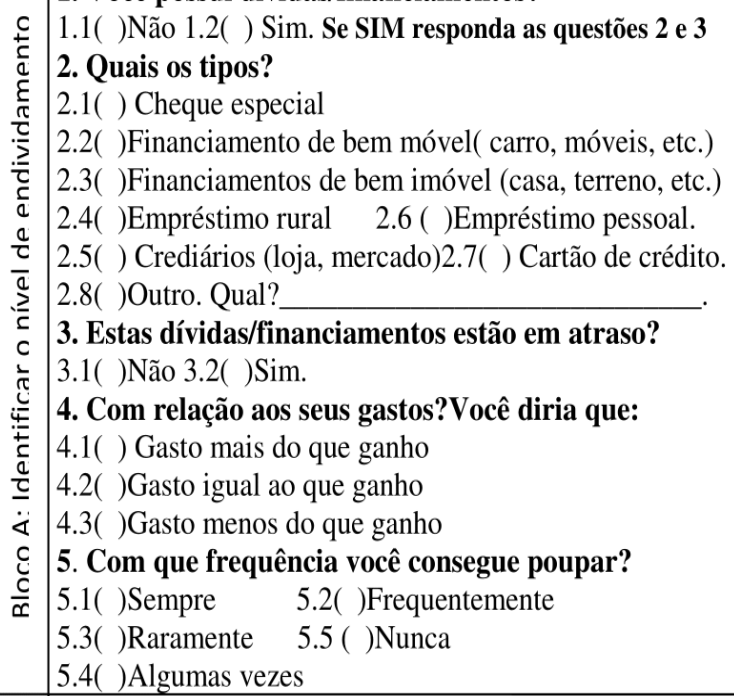

8. Como você se sente a respeito dos seus conhecimentos para gerenciar seu próprio dinheiro?

( )Nada seguro - Eu gostaria de possuir um nível muito melhor de educação financeira.

( )Não muito seguro - Eu gostaria de saber um pouco mais sobre finanças.

( )Mediano - Eu conheço parte do assunto, porém poderia saber mais.

.$\cong \quad$ ( )Razoavelmente seguro - Eu conheço a maioria das coisas que eu precisaria saber sobre o assunto.

( )Muito seguro - Eu possuo conhecimentos bastante amplos sobre finanças.

 conhecimentos para gerir o seu dinheiro?

( ) Em casa com a família.

( )De conversas com amigos.

( ) Em aulas na faculdade.

( ) De revistas, livros, TV e rádio.

( ) De minha experiência prática.

đ̆. Se você tivesse recursos para investir, sem

ter um prazo definido para resgatar, com qual das alternativas abaixo você mais se identificaria como aplicador?

c ( )Ações, pois me agrada a possibilidade altos perdas.

( )Fundos de investimento de risco médio, pois quero um rendimento razoável ainda que com algum risco.

( )Poupança, pois priorizo a segurança em relação ao investimento.

( )Bens (carro, moto, imóvel), pois segurança pra mim é a coisa mais importante.
6. Se possuir dívidas, quanto elas comprometem o seu orçamento?

6.1( )Não possuo

6.2( )Pouco endividado (0-25\%)

6.3( )Em risco $(25-50 \%)$

6.4( ) Sobre-endividado( $>75 \%)$

7. Qual das afirmações seguintes é a mais próxima da quantidade de risco que você está disposto a assumir quando economiza ou faz investimentos?

7.1( )Assumo um risco financeiro considerável, esperando ganhar um retorno considerável.

7.2( )Assumo um risco financeiro acima da média, esperando ganhar um retorno considerável.

7.3( )Assumo um risco financeiro médio, esperando ganhar um retorno médio.

7.4( ) Não desejo assumir risco financeiro.

11. Lindomar e Lindalva têm a mesma

idade. Aos 25 anos, ela começou a aplicar $R \$ 1.000,00$ por ano, enquanto Lindomar não guardava nada. Aos 50, Lindomar percebeu que precisava de dinheiro para sua aposentadoria e começou a aplicar $\mathbf{R} \$$ 2.000,00 por ano, enquanto Lindalva continuou poupando seus $R \$ 1.000,00$. Agora eles têm 75 anos. Quem tem mais dinheiro para sua aposentadoria, se ambos fizeram o mesmo tipo de investimento? ( ) Eles teriam o mesmo valor, já que na prática guardaram as mesmas somas.

( ) Lindomar, porque poupou mais a cada ano.

( ) Lindalva, porque seu dinheiro rendeu por mais tempo a juros compostos.

12. Em relação à sua possível aposentadoria, quais das alternativas abaixo melhor representa sua situação?

( ) Não me preocupei com isso ainda.

( ) Pretendo ter apenas a aposentadoria do governo.

( ) Faço um plano de previdência/poupança própria para aposentadoria.

( ) Tenho planos de começar a poupar para isso.

( ) Não vejo necessidade de poupar para minha aposentadoria. 
13. O quadro abaixo está dividido em três sessões. A $1^{\circ}$ está relacionada com as PRINCIPAIS RAZÕES DAS DÍVIDAS DAS PESSOAS (13) $02^{\circ}$ foca na ESCALA DE MATERIALISMO (14) e o $3^{\circ}$ A PROPENSÃo AO ENDIVIDAMENTO (15). Para cada uma delas indique seu GRAU DE CONCORDÂNCIA utilizando a seguinte escala, SENDO QUE 1 É DISCORDO TOTALMENTE E 10 É CONCORDO TOTALMENTE.

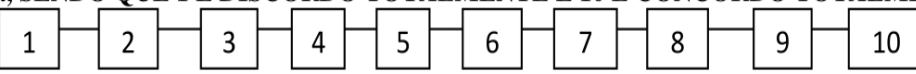

\begin{tabular}{|c|c|c|c|}
\hline & \multicolumn{2}{|c|}{ Se a assertiva não tiver aplicabilidade marque 0} & Notas \\
\hline & \multicolumn{2}{|c|}{ 13.1 Dívida por falta de planejamento. } & \\
\hline & \multicolumn{2}{|c|}{ 13.2 Dívida por desemprego ou queda na renda. } & \\
\hline $\bar{D}$ & \multicolumn{2}{|c|}{ 13.3 Dívida por alta propensão ao consumo. } & \\
\hline 坣 & \multicolumn{2}{|l|}{ 13.4 Dívida por alta taxa de juros. } & \\
\hline & \multicolumn{2}{|l|}{ 13.5 Dívida por empréstimo do nome. } & \\
\hline & \multicolumn{2}{|l|}{ 13.6 Dívida por problemas de saúde. } & \\
\hline & \multicolumn{2}{|l|}{ 13.7 Dívida por má gestão orçamentária. } & \\
\hline$\ddot{1}$ & \multicolumn{2}{|l|}{ 13.8 Dívida por acesso ao crédito. } & \\
\hline$\stackrel{8}{8}$ & \multicolumn{2}{|c|}{ 13.9 Dívida por baixa taxa de juros. } & \\
\hline 0. & \multicolumn{2}{|c|}{ 13.10 Dívida por ausência de desconto à vista. } & \\
\hline . & \multicolumn{2}{|c|}{ 14.1 Eu admiro pessoas que possuem casas, carros e roupas caras. } & \\
\hline 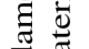 & \multicolumn{2}{|c|}{ 14.2 Eu gosto de gastar dinheiro com coisas caras. } & \\
\hline$\stackrel{\widetilde{g}}{\Xi}$ & \multicolumn{2}{|c|}{ 14.3 Minha vida seria muito melhor se eu tivesse muitas coisas que não tenho. } & \\
\hline$\exists \overline{0}$ & \multicolumn{2}{|c|}{ 14.4 Comprar coisas me dá muito prazer. } & \\
\hline$\frac{\pi}{0}$ & \multicolumn{2}{|c|}{ 14.5 Eu ficaria muito mais feliz se pudesse comprar mais coisas. } & \\
\hline 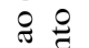 & \multicolumn{2}{|c|}{ 14.6 Eu gosto de possuir coisas que impressionam as pessoas. } & \\
\hline$\stackrel{\overline{0}}{2}$ & \multicolumn{2}{|c|}{ 14.7 Eu gosto de muito luxo em minha vida. } & \\
\hline 要 & \multicolumn{2}{|c|}{ 14.8 Fico incomodado quando não posso comprar tudo que quero. } & \\
\hline$\overline{0} \cdot \frac{\tilde{0}}{5}$ & \multicolumn{2}{|c|}{ 14.9 Gastar muito dinheiro está entre as coisas mais importantes da vida. } & \\
\hline : & 14.10 Compro por impulso. & & \\
\hline 党 & 14.11 Empresto para meus amigos e fan & parte do meu salário. & \\
\hline $\bar{T} 8$ & 15.1 Não é certo gastar mais do que gan & & \\
\hline$\stackrel{0}{0}$ & 15.2. É melhor primeiro juntar dinheirc & pois gastar. & \\
\hline 苞 气 & 15.3. Eu sei exatamente quanto devo em & artão de crédito ou banco. & \\
\hline 象 & 15.4 Acho normal as pessoas ficarem en & as para pagar suas coisas. & \\
\hline$\dot{z}$ & 15.5 Prefiro comprar parcelado a esper & inheiro para comprar à vista. & \\
\hline & 15.6 É importante saber controlar os ga & minha casa. & \\
\hline$\stackrel{\Xi}{\Xi}$ & 15.7 Prefiro pagar parcelado mesmo qu & al seja mais caro. & \\
\hline 巳ี & 15.8 As pessoas ficariam desapontadas & se soubessem que tenho dívida. & \\
\hline$\stackrel{?}{*}$ & 15.9 Não tenho problema em ter dívida & i que posso pagar. & \\
\hline$\ddot{ن}$ & 15.10 Possuo total controle das entradas & s do meu dinheiro. & \\
\hline$\underline{\underline{U}}$ & 15.11 Estou satisfeito com o controle da & $s$ finanças. & \\
\hline & 15.12 Pago minhas contas sem atraso. & & \\
\hline & 15.13 Faço leituras, participo de palestr & educação financeira. & \\
\hline & 16. Gênero:( ) Masculino ( ) Feminino & 22.Qual o seu grau de ensino? & \\
\hline & 17. Idade: ___ anos. & 22.1( )Fundamental Incompleto & \\
\hline & 18. Estado civil & 22.2( )Fundamental Completo & \\
\hline$\overline{\bar{\varepsilon}}$ & 18.1()Casado(a) 18.4( )Divorciado(a) & 22.3( )Ensino Médio Incompleto & \\
\hline 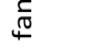 & 18.2( )União estável & 22.4( )Médio completo & \\
\hline$\underline{\underline{T}}$ & 18.3( )Solteiro(a) 18.5( )Viúvo(a) & 20.5( )Superior Incompleto & \\
\hline$\sum_{0}^{2}$ & 19. Possui filhos? & 22.6( ) Superior Completo 20.7 & graduação \\
\hline$\frac{0}{0}$ & 19.1( )Não 19.2( )Sim. Quantos? & 23. Qual é a sua ocupação? & \\
\hline$\underline{\underline{0}}$ & 20. Possui dependentes? & 23.1( )Estudante, qual curso? & \\
\hline $\begin{array}{l}\bar{U} \\
0\end{array}$ & 20.1( )Não 20.2( )Sim. Quantos? & 23.2( )Professor, qual departamer & \\
\hline$\frac{8}{8}$ & 20.3 Quais as idades dos seus filhos/ & 23.3( )Servidor $\quad 23.5($ ) $\mathrm{T}$ & ado \\
\hline$\underbrace{\underline{u}}_{i=\underline{\underline{e}}}$ & dependentes? & 23.4( ) Carteira assinada/empresá & \\
\hline$\frac{\overrightarrow{2}}{2}$ & 21. Sua moradia é? & 24. Renda bruta mensal da sua & (pode ser \\
\hline$\underline{\underline{0}}$ & $\begin{array}{l}\text { 21.1( )Própria 21.2( )Alugada } \\
\text { 21.3( )Financiada }\end{array}$ & $\begin{array}{l}\text { aproximada): } \\
\text { 24.1( )Até } \mathrm{R} \$ 937,00 \text { (1 salário } \mathrm{m}\end{array}$ & \\
\hline ¿ & 21.4( ) Outra. Qual? & 24.2( )De $\mathrm{R} \$ 937,00$ a $\mathrm{R} \$ 2.811$, & s.m) \\
\hline$\frac{0}{\infty}$ & & 24.3( )De $\mathrm{R} \$ 2.811,00$ a $\mathrm{R} \$ 5.62$ & a 6 s.m) \\
\hline & & 24.4( )De $\mathrm{R} \$ 5622,00$ a $\mathrm{R} \$ 8433$, & s.m) \\
\hline & & 24.5( )Acima de $\mathrm{R} \$ 8433,00$ & \\
\hline
\end{tabular}

